\section{Acitretin systemic and retinoic acid $0.1 \%$ cream supression of basal cell carcinoma}

\author{
Xi-Bao Zhang,' San-Quan Zhang,' \\ Chang-Xing Li, 'Zhen-Ming Huang,' \\ Yu-Wu Luo'
}

\author{
'Guangzhou Institute of Dermatology, \\ Guangzhou, China; 'Dongguan Institute of \\ Dermatology, Dongguan, China
}

\begin{abstract}
Retinoids have been used for years as monotherapy and/or in combination for treatment and suppression of cutaneous malignancies in patients with basal cell nevus syndrome, xeroderma pigmentosum, or cutaneous T-cell lymphoma (CTCL) basal cell carcinoma (BCC). We report 4 cases with BCC confirmed by histopathology who were treated by shortterm systemic acitretin combined with retinoic acid $0.1 \%$ cream. The 4 cases with BCC showed good response to the treatment without severe adverse effects during treatment and followup. The finding suggests that acitretin may be an appropriate treatment option for elderly patients who require less invasive treatment for BCC.
\end{abstract}

\section{Introduction}

BCC may be treated by surgery, curettage and electrodesiccation, cryosurgery, Mohs' micrographic surgery, $\mathrm{CO}_{2}$ laser surgery and topical 5-fluorouracil. ${ }^{1-3} \mathrm{~A}$ recent study by Giannotti et al. ${ }^{4}$ demonstrated that topical application of imiquimod $5 \%$ cream and oral acitretin treated a 15-year old boy with xeroderma pigmentosum (XP) who presented with multiple facial BCC previously treated by surgical excision. Acitretin, a recommended treatment option for anogenital warts, has been shown to be effective in treating many other skin disorders, such as human papilloma virus-associated warts and skin carcinomas including BCC. ${ }^{5-8}$ We report a novel method of treating facial BCC patients with oral acitretin and combination with topical application of retinoic acid $0.1 \%$ cream.

\section{Case Reports}

\section{Case \#1}

An 82-year old Chinese man presented with an ulcer on the right nasal wall that persisted for six years. The first appearance of lesion was a brownish papule on the right nasal wall, and size progressively increased with advancing age. The lesion developed into an ulcer with bleeding and pruritus in the past year. Physical examination showed a freckle and sable ulcer, measuring $2 \times 1 \mathrm{~cm}$ in diameter on the right nasal wall. The edge of the lesion has a characteristic rolled border, and hemorrhagic effusion on the surface of the ulcer (Figure 1A). A punch biopsy specimen of the lesion showed nets of basaloid cells infiltrated in the dermis characteristic of peripheral palisading and cleft, which is between tumor focal and matrix (Figure 1B). The patient was treated with oral acitretin at a dose of $30 \mathrm{mg} / \mathrm{d}(0.6$ $\mathrm{mg} / \mathrm{kg}$ ) and topically applied retinoc acid $0.1 \%$ cream two times daily. Within eight weeks, the ulcer had been progressively reduced in size. We reduced the acitretin dose to $20 \mathrm{mg}$ daily $(0.4 \mathrm{mg} / \mathrm{kg})$. The ulcer was completely cleared after six months of treatment (Figure 1C). The patient has undergone follow-up every four weeks for four years and there has been no relapse of the lesion. Skin biopsy revealed no tumor cells in the slide (Figure 1D). During the course of treatment, the patient showed no side effects except mild skin fragility, cheilitis and mild local erythema. On follow-up, laboratory results have remained within normal limits.

\section{Case \#2}

A 70-year old Chinese woman presented with an ulcer she had had on the right temple for five years. The first appearance of lesion was initially reported at the age of 65 years. As the ulcer grew, the lesion developed into an ulcer with bleeding. The lesion was asymptomatic and the size progressively increased with advancing age. In May 2006, the patient presented at our department with increasingly rapid growth of the ulcer with pruritus.

Physical examination showed an ulcer with blood crust measuring $2.0 \times 1.5 \mathrm{~cm}$ in diameter on the right temple. The lesion had a characteristic rolled border (Figure 2A). A punch biopsy specimen of the lesion showed cystic spaces or necrosis in the centre of mass (Figure 2B).The patient was initially treated with oral acitretin at a dose of $20 \mathrm{mg} / \mathrm{d}(0.4$ $\mathrm{mg} / \mathrm{kg}$ ) and topical applied retinoc acid $0.1 \%$ cream two times daily. Within four weeks the size of the lesion had been progressively reduced and the acitretin dose was slowly increased up to $40 \mathrm{mg} / \mathrm{d}(0.8 \mathrm{mg} / \mathrm{kg})$. After 16 weeks, the lesion has disappeared (Figure 2C). Skin biopsy revealed infiltration of lymphocytes around the vessels in dermis and no focal of tumor was seen (Figure 2D). The patient has undergone follow-up every four weeks for two years and there has been no relapse of the lesion. During the course of treatment, the
Correspondence: Xi-Bao Zhang, Department of Dermatology, Guangzhou Institute of Dermatology, Guangzhou 510095, Guangdong Province, P R of China. E-mail: lilichangxing@163.com

Key words: acitretin, basal cell carcinoma.

Conflict of interest: the authors report no conflicts of interest.

Received for publication: 5 September 2009. Revision received: 12 December 2009.

Accepted for publication: 14 December 2009.

This work is licensed under a Creative Commons Attribution 3.0 License (by-nc 3.0).

(C) Copyright X-B Zhang et al., 2010

Licensee PAGEPress, Italy

Dermatology Reports 2010; 2:e4

doi:10.4081/dr.2010.e4

patient showed no side effects except mild skin fragility, cheilitis and mild local erythema. On follow-up, laboratory results have remained within normal limits.

\section{Case \#3}

An 82-year old Chinese woman presented with two nodules on the left temple that had persisted for two years. Two years ago, the patient had had two nodules on the left temple with pruritus and hemorrhagic effusion after scratching. The nodule is characterized by chronicity and gradual enlargement over time. In June 2005, the patient presented at our department with increasingly rapid growth of the ulcer over the last three months.

Physical examination showed two tight conjointed nodules on the left temple, measuring $2.0 \times 2.0 \mathrm{~cm}$ and $1.0 \times 1.0 \mathrm{~cm}$ in diameter, respectively. The center of the lesions had hemorrhagic effusion on the surface of the nodule. The edge of the lesions had a characteristic rolled border (Figure 3A). A punch biopsy specimen of the lesions showed cystic spaces or necrosis in the center of mass (Figure 3B). The patient was prescribed oral acitretin $30 \mathrm{mg}$ two times daily $(1 \mathrm{mg} / \mathrm{kg})$ and topically applied retinoc acid $0.1 \%$ cream two times daily. Two weeks later the size of lesions had been progressively reduced. The lesions were completely clear after eight weeks treatment (Figure 3C). Skin biopsy revealed infiltration of lymphocytes around the vessels in dermis and no focal of tumor cells was seen (Figure 3D). During the course of treatment, the patient did not report any adverse events. The patient has undergone follow-up every four weeks for three years and there has been no relapse of the lesions. During the course of treatment, the patient showed no side effects except mild skin fragility, cheilitis and mild local erythema. On follow-up, laboratory results have remained 
within normal limits.

\section{Case \#4}

A 77-year old Chinese man presented with a pigmented patch on the left nasal wing that had persisted for three years. The first appearance of a lesion was a $0.5 \times 0.5 \mathrm{~cm}$ papula on the left nasal wing that was incorrectly initially diagnosed as seborheic keratosis. The size of the lesion progressively increased with prutitus and bleeding following a slight injury was a common sign. In May 2008, the patient presented at our department with rapidly increasing growth of the lesions over the last six months, and partially infiltrated with obvious pruritus.

Physical examination showed a patch with blood crust measuring $2 \times 1.5 \mathrm{~cm}$ in diameter on the right temple. The edge of the lesion had swollen up with a characteristic rolled border (Figure 4A). Telangiectases were seen through the lesion. A punch biopsy specimen of the lesion showed large islands of tumor predominate (Figure 4B). The patient was prescribed oral acitretin $30 \mathrm{mg}$ two times daily $(1 \mathrm{mg} / \mathrm{kg})$ and topically applied retinoc acid $0.1 \%$ cream two times daily. Two weeks after treatment, the size of lesion had been progressively reduced. The tumor was completely clear at the 6-week follow-up visit (Figure 4C). Skin biopsy revealed epidermis infiltrated by lymphocytes (Figure 4D). The patient has undergone follow-up every four weeks for five months and there has been no relapse of the lesion. During the course of treatment, the patient showed no side effects except mild skin fragility, cheilitis and mild local erythema. On follow-up, laboratory results have remained within normal limits.

\section{Discussion}

BBC lesions are most frequently found on the face ( $85 \%$ are found in the head and neck regions) and especially on the nose. Excessive sunlight exposure, chemical cocarcinogens, and genetic determinants are implicated as causes of BBC. ${ }^{1}$ For this reason it is mostly seen in middle-aged and elderly subjects. In the current cases, the lesion found on the nose and temple suggest common features of BCC. Systemic therapy including cisplatin, doxorubicin, cyclophosphamide, and adriamycin have all been used in various degrees. No single treatment method is ideal for all lesions, such as biopsy, excision, Mohs' microsurgery, ionizing radiation, cryosurgery, curettage, electrosurgery, laser therapy, or topical cytotoxic therapy such as 5-fluorouracil. These methods, although effective on isolated carcinomas, are not ideal treating facial BCC, primarily because of a higher risk of causing disfiguring scarring. ${ }^{1,4,5}$ The aim in treatment is for a per-

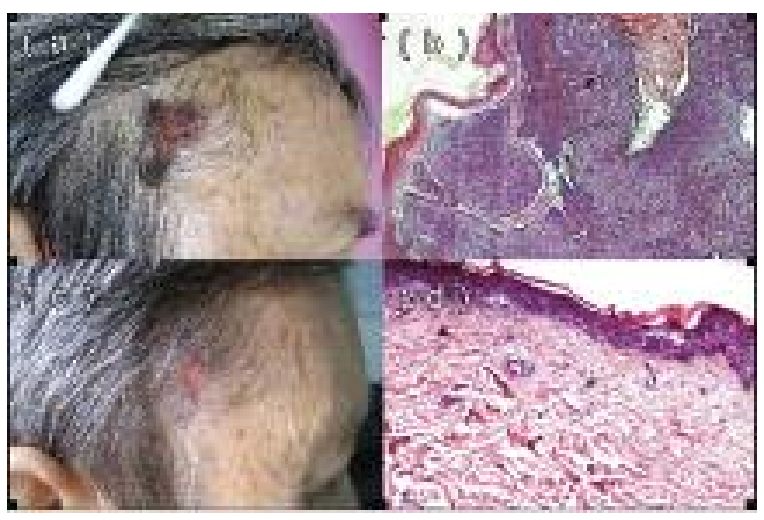

Figure 1 (A) A freckle and sable ulcer, measuring $2 \mathrm{~cm} \times 1 \mathrm{~cm}$ in diameter on the right nasal wall. (B) Histology showed nets of basaloid cells infiltrated in the dermis $(\times 200)$. (C) The tumor was completely cleared at the 6-month follow-up visit. (D) After treatment, there are no tumor cells in this slide (×100).

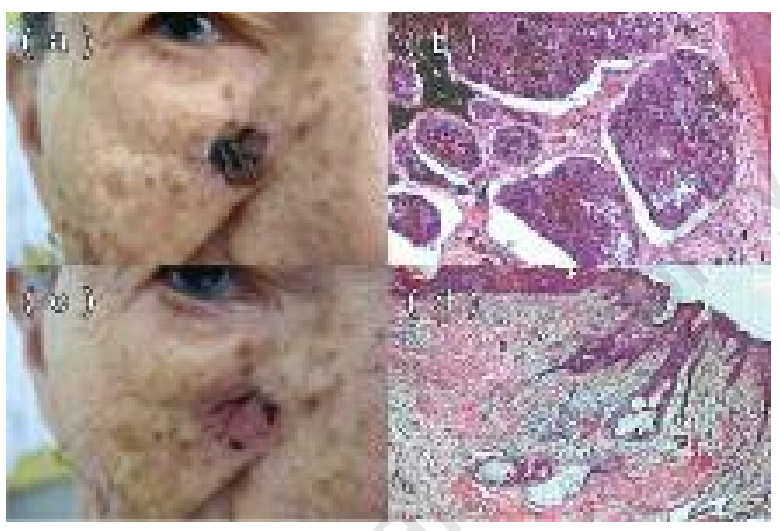

Figure 2 (A) An ulcer with blood crust, measuring $2.0 \mathrm{~cm} \times 1.5 \mathrm{~cm}$ in diameter on the right temple. (B) Histology showed cystic spaces or necrosis in the centre of mass $(\times 100)$. (C) The tumor was completely cleared at the 4-month follow-up visit. (D) Skin biopsy revealed infiltration of lymphocytes around the vessels in dermis, and no focal of tumor being seen $(\times 100)$.

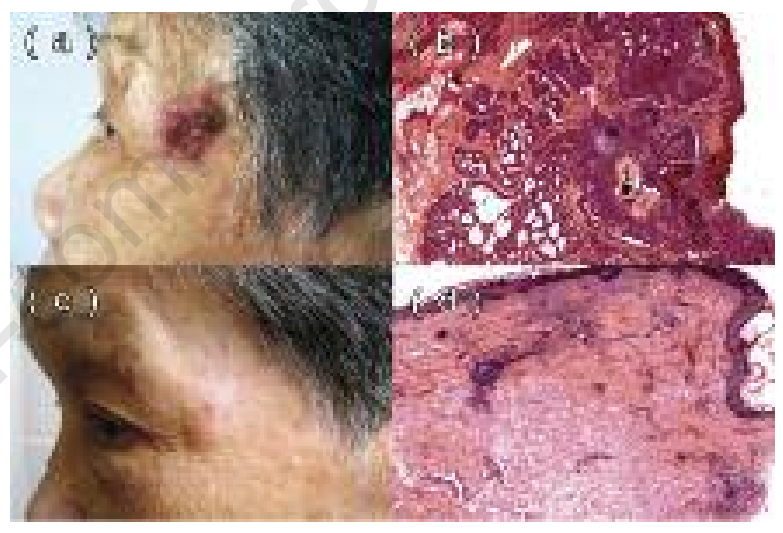

Figure 3 (A) Two tightening conjointed nodules on the left temple, measuring $\mathbf{2 . 0}$ $\mathrm{cm} \times 2.0 \mathrm{~cm}$ and 1.0 $\mathbf{c m} \times 1.0 \mathrm{~cm}$ in diameter, respectively. (B) A punch biopsy specimen of the lesion showed cystic spaces or necrosis in the centre of mass (x100). (C) The tumor was completely cleared at the 8-week follow-up visit. (D) Skin biopsy revealed infiltration of lymphocytes around the vessels indermis, and no focal of tumor cell being seen $(\times 40)$.

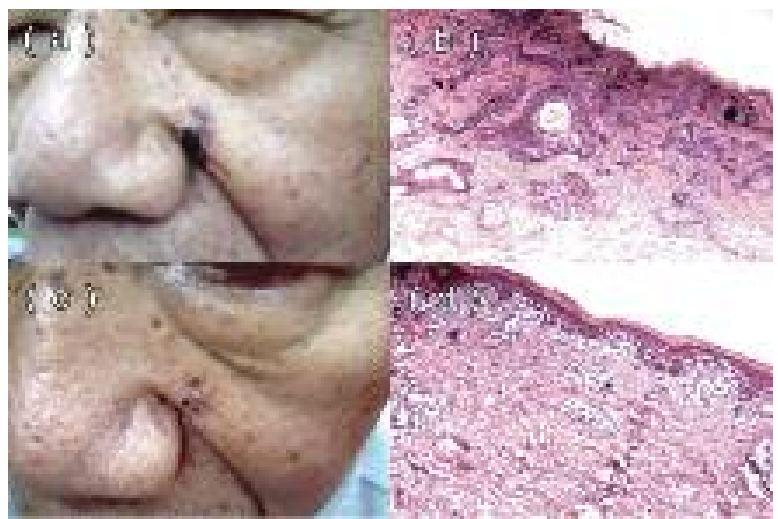

Figure 4 (A) A patch with blood crust, measuring $2 \mathrm{~cm} \times 1.5 \mathrm{~cm}$ in diameter on the right temple. (B) Histology showed large islands of tumor predominate $(\times 100)$. (C) The tumor was completely cleared at the 8-week follow-up visit. (D) Skin biopsy revealed epidermis was infiltrated by lymphocytes $(\times 100)$. 
manent cure with the best cosmetic results, important because the most frequent site of the basal cell carcinoma is the face.

Retinoids, natural and synthetic derivatives of vitamin A, are biological regulators of differentiation, proliferation, apoptosis, and immune response. ${ }^{9}$ Retinoic acid receptor selective retinoids have been used for years as monotherapy and/or in combination for treatment of CTCL and BBC. ${ }^{9-12}$ Recently, one case report showed that a 15 -year old boy with XP presented with multiple facial BCC because of the risk of scarring, and the patient refused further surgery. As an alternative, three times weekly application of imiquimod $5 \%$ cream in combination with oral acitretin (20 mg daily) was prescribed for 4-6 weeks. All tumors had resolved at the 6-month follow-up visit, highlighting the therapeutic potential with a combination of oral acitretin and imiquimod 5\% cream. ${ }^{4}$ Ingves et al. also reported a 48 -year old woman with BCC who was successfully treated with topical imiquimod and systemic acitretin. ${ }^{13}$ This evidence suggests that acitretin combination with imiquimod seem to be possible when treating superficial tumors in areas where the cosmetic outcome is particularly important.

In the current 4 cases of BCC confirmed by clinical and histopathology, the patients refused surgery. As an alternative, twice daily application of retinoic acid $0.1 \%$ cream in combination with oral acitretin (0.4-1 mg/kg daily) was prescribed after appropriate discussion with the patient and his or her sons. During follow-up, laboratory results remained within normal limits and examined by histopathology on completion of therapy. The 4 cases showed good response to the treatment without severe adverse effects. All cases have been followed up to date with no evidence of recurrence. This evidence highlights the therapeutic potential of oral acitretin for BCC.

\section{References}

1. Drake LA, Ceilley RI, Cornelison RL, et al. Guidelines of care for basal cell carcinoma. The American Academy of Dermatology Committee on Guidelines of Care. J Am Acad Dermatol 1992;26:117-20.

2. Kopera D, Cerroni L, Fink-Puches R, et al. Different treatment modalities for the management of a patient with the nevoid basal cell carcinoma syndrome. J Am Acad Dermatol 1996;345:937-9.

3. Hamouda B, Jamila Z, Najet R, et al. Topical 5-fluorouracil to treat multiple or unresectable facial squamous cell carcinomas in xeroderma pigmentosum. J Am Acad Dermatol 2001;44:1054.

4. Giannotti B, Vanzi L, Difonzo EM, et al. The treatment of basal cell carcinomas in a patient with xeroderma pigmentosum with a combination of imiquimod $5 \%$ cream and oral acitretin. Clin Exp Dermatol 2003;28:33-5.

5. Edwards L, Ferenczy A, Eron L, et al. Self- administered topical 5\% imiquimod cream for external anogenital warts. Arch Dermatol 1998;134:25-30.

6. Hengge UR, Esser S, Schultewolter T, et al. Self-administered topical 5\% imiquimod for the treatment of common warts and molluscum contagiosum. Br J Dermatol 2000;143:1026-31.

7. Schroeder TL, Sengelmann RD. Squamous cell carcinoma in situ of the penis successfully treated with imiquimod $5 \%$ cream. J Am Acad Dermatol 2002;46:545-8.

8. Beutner KR, Geisse JK, Helman D, et al. Therapeutic response of basal carcinoma to the immune response modifier imiquimod 5\% cream. J Am Acad Dermatol 1999;41:1002-7.

9. Duvic M, Cather JC. Emerging therapies in CTCL. Clin Dermatol 2000;18:147-56.

10. Zackheim HS. Treatment of cutaneous Tcell lymphoma with retinoids. Dermatol Ther 1998;8:15-20.

11. Zhang C L, Duvic M. Treatment of cutaneous T-cell Lymphoma with retionids. Dermato Therap 2006;19:264-71.

12. Chen K, Craig JC, Shumack S. Oral retinoids for the prevention of skin cancers in solid organ transplant recipients: a systematic review of randomized controlled trials. Br J Dermatol 2005;152:51823.

13. Ingves C, Jemec GB. Combined imiquimod and acitretin for non-surgical treatment of basal cell carcinoma. Scand J Plast Reconstr Surg Hand Surg 2003;37:293-5. 